\title{
COMPARISON OF FOUR METHODS FOR CORNEAL THICKNESS MEASUREMENT
}

\section{Teodora L. Marinova, Vesela Ivancheva, Svilena S. Peeva, Christina N. Grupcheva}

Department of Ophthalmology and Visual Science, Medical University - Varna, Specialised Eye Hospital - Varna, Bulgaria

Corresponding Author:

Christina N. Grupcheva

Medical University - Varna, Department of Ophthalmology and Visual Science

Specialised Eye Hospital - Varna, 15, Doyran str.

9002,Varna

Bulgaria

e-mail:_marinova.teodora@yahoo.fr

Received: November 21, 2012

Revision received: March 12, 2013

Accepted: June 26, 2013

\section{Summary}

The aim of the study was to evaluate the thickness of the normal cornea in order to establish correlation between four methods of measuring including: ultrasound pachymetry (USP), anterior segment optical coherence tomography (ASOCT), non-contact tono/pachymetry (TONOPACHY) and laser-scanning confocal microscopy (LSCM). The study was based on evaluating repeatability and comparability of four different methods for measuring the corneal thickness. Non contact specular microscopy was first performed on all 27 patients (aged between 20 and 24 years) to evaluate corneal characteristics and confirm the absence of pathological changes. Each participant was examined by USP, ASOCT and TONOPACHY, and 13 eyes of 10 persons were also examined by LSCM. The values of average central corneal thickness measured by USP, ASOCT, TONOPACHY and LSCM were 532.20 $\pm 4.5 \mu \mathrm{m}$, $553.33 \pm 12.1 \mu \mathrm{m}$, were $548.20 \pm 5.62 \mu \mathrm{m}$ and $573.33 \pm 7.22$ $\mu \mathrm{m}$, respectively. There was a high correlation between the instruments. The mean differences for central corneal thickness measurements were $41.43 \pm 1.67 \mu \mathrm{m}$ between USP and LSCM, 20.43 $\pm 2.4 \mu \mathrm{m}$ between USP and ASOCT, and $22.1 \pm 3.88 \mu \mathrm{m}$ between USB and TONOPACHY. Anterior segment optical coherence tomography overestimated corneal thickness as compared with that measured by USP, which is believed to be a gold standard. Anterior segment optical coherence tomography had better agreement with USP, as compared with LSCM. However, the results of measured cornea thickness by TONOPACHY were very close to cornea thickness measured by ASOCT.

Key words: cornea thickness, pachymetry, optical coherence tomography, confocal microscopy

\section{Introduction}

The measurement of central corneal thickness has become increasingly important in ophthalmic practice[1]. Central corneal thickness (CCT) measurement is an essential part of diagnostic and therapeutic approaches to corneal pathology. Corneal thickness measurement method should be repeatable and reproducible to be accepted as an ideal method. This method should be preferably noncontact and safe, as well as quick and easy to perform. The measurement of corneal thickness has 
various important applications. Monitoring central corneal thickness is important for diagnosing and standing of ectatic dystrophies such as keratoconus, and calculating the risk of glaucoma progression in ocular hypertension patients $[2,3]$. It is also essential for preoperative risk selection and planning of refractive surgical procedures.

Traditional methods of corneal thickness measurement use spot pachymetry techniques. Ultrasound pachymeter is one such method. It is a method both cheap and easy to use for corneal measurement [4]. Many other instruments can assess CCT, e.g. ultrasound pachymetry(USP) or ultrasound biomicroscopy (UBM), specular and confocal microscopy, slip-scanning corneal topography, the Scheimpflug system, optical biometry, and optical coherence tomography (OCT). In vivo laser scanning confocal microscopy (LSCM) is a new non-invasive technology, which is useful as a supplementary diagnostic tool for in vivo assessment of the histopathology of many ocular surface disorders. This technology allows observation of all cornea levels. Ultrasound pachymetry used to be a gold standard for measuring corneal thickness. It is a contact method and the result of measurement strongly depends on the operator technique [5]. The precision of measurements is estimated by two terms: reproducibility and repeatability. Reproducibility is the variability of results obtained from one object using the same device in different measurement conditions. The variability of results obtained from one object in the same measurement conditions (time, instrument, technique, place, and operator) defines repeatability [6].

The purpose of this study was to evaluate the thickness of normal cornea in order to establish correlation between four methods of measuring including: ultrasound pachymetry (USP), anterior segment optical coherence tomography (ASOCT), non-contact tono/pachymetry (TONOPACHY) and Laser-scanning confocal microscopy (LSCM).

\section{Materials and Methods:}

The study was based on evaluating repeatability and comparability of four different methods for measuring the corneal thickness. Non contact specular microscopy was first performed on all 27 adults to evaluate corneal characteristics and confirm that there were no pathological changes.
The mean age of the study group patients was $21.2 \pm 1.35$ years (range 20-24 years). The group included 23 female $(85.2 \%)$ and 4 male $(14.8 \%)$ patients. Each patient was examined by ultrasound pachymetry (USP), anterior segment optical coherence tomography (ASOCT), noncontact tono/pachymetry (TONOPACHY). Ten persons with 13 eyes were examined by Laserscanning confocal microscopy (LSCM) and the other three methods.

\section{In vivo laser scanning confocal microscopy examination}

In vivo confocal microscopy enables detailed analysis of the human cornea, allowing detailed visualization of the corneal microstructure. The LSCM uses a coherent high intensity light source and the laser beam is scanned over the back of the microscope objective by a set of galvanometer scanning mirrors. In this study we used Heidelberg Retina Tomography/Rostock Cornea Module (Heidelberg Engineering Gmbh, Germany), which is an applanating device. A 63x water immersion objective lens (Zeiss) is used with a $670 \mathrm{~nm}$ wavelength Class I diode laser as a light source to allow a scanning area of $300 \times 300$ $\mu \mathrm{m}(\mathrm{FOV}-300 \mu \mathrm{m})$, with a lateral resolution of 1 $\mu \mathrm{m} /$ pixel and z-resolution of $4 \mu \mathrm{m}$ and up to $800 \mathrm{x}$ magnification. The objective of the microscope was covered with a disposable sterile PMMA cap previously filled with eye gel (Corneregel) in order to provide immersion. One drop of topical anesthetic (Alcain 0, 5\%) was applied in the inferior cul-de-sac of the eye to be examined. The patient was positioned in front of the instrument, his/her chin and forehead adjusted against the headrests. The instrument was justified using the inbuilt software. The objective of the microscope was subsequently advanced to achieve a contact with the ocular surface; the position of the eye was monitored by a camera placed on the side of the objective.

Two hours after in vivo confocal microscopy other measurements were performed in the following order:

\section{Optical coherent tomography examination} Optical coherent tomography was performed using 3D Topcon 2000 OCT with lateral resolution of $\leqslant 20 \mu \mathrm{m}$ and in-depth resolution of $5 \mu \mathrm{m}-6 \mu \mathrm{m}$. Optical coherence tomography (OCT) is a non-contact imaging method based on principles of low-coherence interferometry. Operating distance for anterior segment (AS) photography was $63,7 \mathrm{~mm}$ (with anterior 
segment special forehead rest); scan speed was 27000 A-scans per second; scanning range on cornea $6 \times 6 \mathrm{~mm}$. A standardized scanning protocol was performed for each patient. High resolution anterior segment OCT scans 12 radial (1024 A line) and 3D (6x6mm, 512x128) were carried out. All exams were performed with centering on the visual axis. A longer wavelength light source is used in anterior segment (AS)-OCT. That imaging technique allows higher resolution imaging of the anterior and posterior cornea surfaces. This new generation high-speed scanning system exceeds the generation of pachymetric maps $[7,8]$.

\section{Tono/pachymetry examination}

The Non-Contact Tonometer/Pachymeter is the integrated pachymeter/tonometer, combining the measurement of intraocular pression (IOP) and CCT in one instrument. This IOP measurement is easy, quick and accurate. Non-contact pachymetry is a reliable method, easy to use and without subjective factor of the operator measurement skills. The tono/pachymetry was designed in response to numerous clinical studies. All these studies have shown the importance of simultaneous measurement of central corneal thickness and intraocular pressure. Tono/pachymetry readings were taken first to avoid any potential disturbance caused by corneal contact in the ultrasonic pachymetry. For examination the patient was positioned with the chin in a cup and forehead against a headband. The CCT was measured while the subject focused on a fixation light in the instrument. After proper positioning of the alignment dot, circle, and bar on the screen, pachymetry was performed [9].

\section{Ultrasound Pachymetry examination}

Ultrasound Pachymetry thickness was executed using an A-scan ultrasonic pachymetry. This instrument was precalibrated for all measurements. Alcain ( $0.5 \%$ collyr, Alcon) was used for topical anesthesia. All the patients were seated upright and the handheld probe of ultrasound pachymetry examination was aligned as perpendicularly as possible on the central cornea. Twelve readings were obtained and averaged.

\section{Results}

The group included 23 female $(85.2 \%)$ and 4 male $(14.8 \%)$ patients. The mean age of the study group was 21.2 \pm 1.35 years (range, 20-24 years).

The results of Mean Central Corneal Thickness are shown in Table 1.

Table 1. Mean central corneal thickness values in all 27 examined eyes in healthy patients with four different methods

\begin{tabular}{ll}
\hline Method of Measurement & $\begin{array}{l}\text { Mean Central Corneal } \\
\text { Thickness }(\boldsymbol{\mu m} \pm \text { SD) }\end{array}$ \\
\hline Ultrasound pachymetry (USP) & $532.20 \pm 4.5 \mu \mathrm{m}$ \\
\hline Anterior segment optical coherence tomography (ASOCT) & $553.33 \pm 12.1 \mu \mathrm{m}$ \\
\hline Non contact tono/pachymetry (TONOPACHY) & $548.20 \pm 5.62 \mu \mathrm{m}$ \\
\hline Laser-scanning confocal microscopy (LSCM) & $573.33 \pm 7.22 \mu \mathrm{m}$ \\
\hline
\end{tabular}

There was high correlation between instruments The CCT measurements were significantly deeper with the LSCM than other three methods. The lowest value of CCT was measured by USP. The mean differences for central corneal thickness measurements were $41.43 \pm 1.67 \mu \mathrm{m}$ between USP and LSCM, $20.43 \pm 2.4 \mu \mathrm{m}$ between USP and ASOCT, and $22.1 \pm 3.88 \mu \mathrm{m}$ between USB and TONOPACHY. Table 2 shows the interdevice differences. The results of measured cornea thickness by TONOPACHY are very close to cornea thickness measured by ASOCT. The biggest alternation between the given results is this measured by LSCM. LSCM overestimates with more than 40 $\mu \mathrm{m}$ the USP mean value.

ASOCT had better agreement with USP, as compared with LSCM. The results of LSCM measurements shown the biggest values and overestimated corneal thickness compared with that measured with USP. In the same time ASOCT overestimated corneal thickness compared with that measured with USP, which is believed to be a gold standard. 
Table 2. Interdevice difference between CCT measurements

\begin{tabular}{ll}
\hline Devices & Difference \\
\hline USP / LSCM & $41.43 \pm 1.67 \mu \mathrm{m}$ \\
\hline USP / AS-OCT & $20.43 \pm 2.4 \mu \mathrm{m}$ \\
\hline USP / Tono-Pachymetry & $22.1 \pm 3.88 \mu \mathrm{m}$ \\
\hline
\end{tabular}

\section{Discussion}

Accurate measurement of CCT has become important with the rapidly increasing popularity of corneal refractive surgical procedures and with the implantation of new (phakic) intraocular lenses. In this study, we have compared four different: two noncontact and two contact optical methods of measuring CCT. Three of these instruments, the LSCM, the ASOCT and the noncontact tonopachymetry have been made commercially available only quite recently. The clinical importance of corneal thickness measurement is increasing. It is useful for diagnosing and monitoring. The value of intraocular pressure is in correlation with corneal thickness and the thickness of the cornea is important for calculating glaucoma progression risk in patients with ocular hypertension. Underestimation of intraocular pressure may lead to thinner corneas [10-14].

The ultrasound pachymetry(USP) has been considered a gold standard for corneal thickness measurement for many years [15-17]. It is a contact method. However, many other methods, including AS-OCT and TONOPACHY have the great advantage of noncontact. These methods use different measurement technologies. Their results are also different. According to different researchers, CCT measurement obtained with standard ultrasound pachymetry varies from 542 to $550 \mu \mathrm{m}$ [17-20]. In our case, the mean CCT measured by the non-contact pachymetry was $548.20 \pm 5.62 \mu \mathrm{m}$. This result is very close to the result of CCT by ASOCT. Our result of ASOCT measurements was $548.20 \pm 5.62 \mu \mathrm{m}$. In the literature, the mean CCT previously reported was within the range of 523-527 $\mu \mathrm{m}$. The CCT was measured by different types of OCT instruments $[21,22]$.

We decided to use US pachymetry as the reference for CCT measurement in our study because new topography devices are calibrated against the US pachymeter. However, as Bourne and McLaren [22] point out, the most accurate pachymetry measurements can be obtained with optical pachymeters, such as the one described by Maurice and Giardini [23] Nevertheless, ultrasonic pachymeters are fast, simple to use, and widely available, and they provide repeatable measurements, explaining why many recent studies use this method as a reference [24-26].

Piotrowiak reported mean results of CCT measured by AS-OCT was lower than results from USP[9]. These results correspond with other studies with Pentacam HR and ASOCT measurements. The results were lower than ultrasound pachymetry measurements. There is a hypothesis that the topical anesthetics used in contact measurement with the ultrasound pachymeter may cause corneal epithelial edema and overestimation of the values of the CCT [27].

However, there are also studies $[9,28]$ showing just the opposite correlation. Results from ultrasound pachymetry are lower in comparison to other methods. The ultrasound pachymetry causes tear film dislocation and epithelium compression. CCT measurements are lower by $7-30 \mu \mathrm{m}$.

Wong and coauthors [29] compared central corneal thickness measurements of Orbscan (also with an acoustic factor of 0.92), USP, and OCT. The measured central corneal thickness was similar for Orbscan $(555.96 \pm 32.41 \mu \mathrm{m})$ and USP $(555.11 \pm 35.30 \mu \mathrm{m})$ and thinner for OCT $(523.21 \pm 33.54 \mu \mathrm{m})$.

In vivo laser scanning confocal microscopy (LSCM) is a new non-invasive technology useful as a supplementary diagnostic tool for in vivo assessment of the normal structure or histopathology of the cornea. Jalbert describe in vivo laser scanning examination principle of normal cornea examination. Confocal microscopes can be used to measure corneal thickness [29-33]. This function is called confocal microscopy through focusing (CMTF) on the TSCM (tandem scanning confocal microscope) [30]. Briefly, rapid movement of the objective lens itself [31] or of the focus of the objective lens [30] in the Z-axis is automated and registered by a computer. The amount of light backscattered by the central section of each image is also recorded, allowing the generation of an intensity profile curve. Specialized software allows interactive viewing of the image corresponding to the cursor location on the Zcurve and measurement of the distance between any two points on the curve. Because different layers of the cornea reflect light at different intensities, the depth-intensity profile allows for 
the determination of corneal sub layer location. As well as corneal thickness, measurements of epithelial thickness, Bowman's layer thickness, and following laser in situ keratomileusis (LASIK) surgery, flap thickness can also be obtained[30,32].

In this study, we measured only normal corneas of healthy subjects. Therefore, we do not have data concerning the agreement between the four methods when measuring corneas with pathological alterations, or postoperative corneas.

\section{References}

1. Barkana Y, Gerber Y, Elbaz U, Schwartz S, KenDror G, Avni I, et al. Central corneal thickness measurement with the Pentacam Scheimpflug system, optical low-coherence reflectometry pachymeter, and ultrasound pachymetry. J Cataract Refract Surg. 2005;31(9):1729-35.

2. Doughty MJ, Zaman ML. Human corneal thickness and its impact on intraocular pressure measures: a review and meta-analysis approach. Surv Ophthalmol. 2000;44(5):367-408.

3. Gordon MO, Beiser JA, Brandt JD, Heuer DK, Higginbotham EJ, Johnson CA, et al. The Ocular Hypertension Treatment Study: baseline factors that predict the onset of primary open-angle glaucoma. Arch Ophthalmol. 2002;120(6):71420.

4. Wheeler NC, Morantes CM, Kristensen RM, Pettit TH, Lee DA. Reliability coefficients of three corneal pachymeters. Am J Ophthalmol. 1992; 113(6):645-51.

5. Al-Mezaine HS, Al-Amro SA, Kangave D, Sadaawy A, Wehaib TA, Al-Obeidan S. Comparison between central corneal thickness measurements by oculus pentacam and ultrasonic pachymetry. Int Ophthalmol. 2008; 28(5):333-8.

6. Taylor JR. An Introduction to Error Analysis: The Study of Uncertainties in Physical Measurements. 2nd ed. Sausalito, Calif. USA: University ScienceBooks; 1997. p. 5-55.

7. Muscat S, McKay N, Parks S, Kemp E, Keating D. Repeatability and reproducibility of corneal thickness measurements by optical coherence tomography. Invest Ophthalmol Vis Sci. 2002;43(6):1791-5.

8. Izatt JA, Hee MR, Swanson EA, Lin CP, Huang D, Schuman JS, et al. Micrometer-scale resolution

\section{Conclusion}

In conclusion, we have shown that ASOCT overestimated corneal thickness compared with that measured with USP, which is believed to be a gold standard. Also ASOCT had better agreement with USP, as compared with LSCM. However the results of measured cornea thickness by TONOPACHY are very close to cornea thickness measured by ASOCT.

Further research is needed to estimate central corneal thickness measurements by these technologies and come to a conclusion whether USP results are more or less clinically useful than others.

imaging of the anterior eye in vivo with optical coherence tomography. Arch Ophthalmol. 1994;112(12):1584-9.

9. Piotrowiak I, Soldanska B, Burduk M, Kaluzny B, Kaluzny J. Measuring Corneal Thickness with SOCT, the Scheimpflug System, and Ultrasound Pachymetry. ISRN Ophthalmology Volume 2012 (2012), Article ID 869319, 5 pages doi:10.5402/2012/869319.

10. M. Shaheeda, Lee GKY, Rao SKR, Wong AL, Cheng AC, Li EY, et al. Repeatability and reproducibility of pachymetric mapping with Visante Anterior Segment-Optical Coherence Tomography. Invest Ophthalmol Vis Sci. 2007;48(12): 5499-504.

11. Doughty MJ, Zaman ML. Human corneal thickness and its impact on intraocular pressure measures: A review and meta-analysis approach. Surv of Ophthalmol. 2000;44(5): 367-408.

12. Medeiros FA, Sample PA, Weinreb RN. Corneal thickness measurements and visual function abnormalities in ocular hypertensive patients. Am J Ophthalmol. 2003;135(2):131-7.

13. Miglior S, Albe E, Guareschi M, Mandelli G, Gomarasca S, Orzalesi N. Intraobserver and interobserver reproducibility in the evaluation of ultrasonic pachymetry measurements of central corneal thickness. Br J Ophthalmol. 2004;88(2): 174-7.

14. Kitsos G, Gartzios C, Asproudis I, Bagli E. Central corneal thickness in subjects with glaucoma and in normal individuals (with or without pseudoexfoliation syndrome). Clin Ophthalmol. 2009;3(1): 537-42.

15. Cairns G, McGhee CNJ. Orbscan computerized topography: attributes, applications, and limitations. J Cataract Refract Surg. 2005; 31(1):205-20. 
16. Iskander NG, Anderson Penno E, Peters NT, Gimbel HV, Ferensowicz M. Accuracy of Orbscan pachymetry measurements and DHG ultrasound pachymetry in primary laser in situ keratomileusis and LASIK enhancement procedures. J Cataract Refract Surg. 2001;27(5):681-5.

17. Chakrabarti HS, Craig JP, Brahma A, Malik TY, McGhee CNJ. Comparison of corneal thickness measurements using ultrasound and Orbscan slitscanning topography in normal and post-LASIK eyes. J Cataract Refract Surg. 2001; 27(11):18238.

18. Gherghel D, Hosking SL, Mantry S, Banerjee S, Naroo SA, Shah S. Corneal pachymetry in normal and keratoconic eyes: Orbscan II versus ultrasound. J Cataract Refract Surg. 2004; 30(6):1272-7.

19. Buehl W, Stojanac D, Sacu S, Drexler W, Findl O. Comparison of three methods of measuring corneal thickness and anterior chamber depth. Am J Ophthalmol. 2006; 141(1):7-12.

20. GeggelHS, TalleyAR. Delayed onset keratectasia following laser in situ keratomileusis. J Cataract Refract Surg. 1999; 25(4):582-6.

21. Lattimore MR Jr, Kaupp S, Schallhorn S, Lewis R IV. Orbscan pachymetry; implications of a repeated measures and diurnal variation analysis. Ophthalmology. 1999;106(5):977-81.

22. Bourne WM, McLaren JW. Clinical responses of the corneal endothelium. Exp Eye Res. 2004; 78(3):561-72.

23. Maurice DM, Giardini AA. A simple optical apparatus for measuring the corneal thickness, and the average thickness of the human cornea. Br J Ophthalmol. 2012;35(3):169-77.

24. Hashemi H, Mehravaran S. Central corneal thickness measurement with Pentacam, Orbscan II, and ultrasound devices before and after laser refractive surgery for myopia. J Cataract Refract Surg. 2007;33(10):1701-7.

25. Bourges JL, Alfonsi N, Lalibert JF, Chagnon M, Renard G, Legeais J-M, et al. Average 3dimensional models for the comparison of Orbscan II and Pentacam pachymetry maps in normal corneas. Ophthalmology. 2009; 116(11):2064-71.
26. Jahadi HR, Katbab A, Khalili MR, Abtahi MB. Comparison of corneal thickness measurements using Galilei. Cornea. 2010;29(10):1091-5.

27. Ho T, Cheng ACK, Rao SK, Lau S, Leung CKS, Lam DSC. Central corneal thickness measurements using Orbscan II, Visante, ultrasound, and Pentacam pachymetry after laser in situ keratomileusis for myopia. J Cataract Refract Surg. 2007;33(7):1177-82.

28. Tam ES and Rootman DS. Comparison of central corneal thickness measurements by specular microscopy, ultrasound pachymetry, and ultrasound biomicroscopy. J Cataract Refract Surg. 2003;29(6):1179-84.

29. Wong ACM, Wong CC, Yuen NSY, Hui SP. Correlational study of central corneal thickness measurements on Hong Kong Chinese using optical coherence tomography, Orbscan and ultrasound pachymetry. Eye (Lond). 2002; 16(6):715-21.

30. Jalbert I, Stapleton F, Papas E, Sweeney DF, CoroneoM. In vivo confocal microscopy of the human cornea. Br J Ophthalmol. 2003;87(2):22536.

31. Li HF, Petroll WM, Møller-Pedersen T, Maurer JK, Cavanagh HD, Jester JV. Epithelial and corneal thickness measurements by in vivo confocal microscopy through focusing (CMTF). Curr Eye Res. 1997;16(3):214-21.

32. Jalbert I, Papas E, Sweeney DF, Stapleton F. Instrument, diurnal, and day to day repeatability of in vivo measurements of the central human cornea using slit scanning confocal microscopy and modified optical pachometry. Invest Ophthalmol Vis Sci. 2002;43:E-Abstract 1713.

33. Vesaluoma M, Pérez-Santonja J, Petroll WM, Linna T, Alió J, Tervo T. Corneal stromal changes induced by myopic LASIK. Invest Ophthalmol Vis Sci. 2000;41(2):369-76.

34. Stave J, Slowik C, Somodi S, et al. Keratocyte density in the in vivo cornea. Automatic quantification with a modified confocal microscope MICROPHTHAL. Klin Monatsbl Augenheilkd. 1998;213:38-44. 